\title{
Design and Analysis of a Smart Blind Stick for Visual Impairment
}

\author{
Zulkhairi Mohd Yusof ${ }^{1}$, Md Masum Billah ${ }^{2}$, Kushsairy Kadir ${ }^{3}$, Muhamad Amirul Sunni Bin Rohim ${ }^{4}$, \\ Haidawati Nasir ${ }^{5}$, M. Izani ${ }^{6}$, A. Razak ${ }^{7}$ \\ 1,2,3,4,5 Universiti Kuala Lumpur (UniKL), Kuala Lumpur, Malaysia \\ ${ }^{6,7}$ Visual \& Digital Production Dept., College of Architecture, Effat University, Jeddah, Saudi Arabia
}

\section{Article Info \\ Article history: \\ Received Apr 21, 2018 \\ Revised Apr 24, 2018 \\ Accepted Jun 14, 2018}

Keywords:

Hole Detection

Smart Blind Stick

Visual Impaired

\begin{abstract}
For a long time, visually impaired person uses a white cane to guide their way when travel outside. The white cane has been useful for the blinds in improving their mobility but unfortunately the white cane has its limitation. One of the shortcomings of the white cane is that, it could only detect the obstacles that are within the contact ranges of the white cane. This problem sometimes could cause the blind person to be in trouble because of insufficient time to detect and warn new obstacles in front of the blind person. This research proposes a walking stick system that has two functions; to classify an obstacles height whether it is low or high and to detect a front hole. The ability to detect the height of an obstacle will help the visually impaired to either step over or avoid the obstacle. The ability to detect a hole should help the visually impaired to avoid it in time. The walking stick will use two ultrasonic sensors for the detection of obstacle height, and a laser sensor for the detection of hole. A controller will be used to monitor and analyze the data from the sensors and feedback to the user through a vibration sensor and buzzer. The algorithm to differentiate the height of obstacles is working well and it is able to differentiate high or low obstacles. The laser ranging sensor has successfully been tested for hole detection. Therefore, the walking stick with ultrasonic and laser sensors will help more visually impaired to move around much faster and feeling more safer due to improved warning system for their movement.
\end{abstract}

Copyright $@ 2018$ Institute of Advanced Engineering and Science. All rights reserved.

Corresponding Author:

Md Masum Billah,

Universiti Kuala Lumpur (UniKL),

Kuala Lumpur, Malaysia.

Email: drmdmasum@unikl.edu.my

\section{INTRODUCTION}

Visually impaired people are mostly suffered from the brain information processing inactivity due to the lack of visual input to the brain [1]. Therefore, it results the difficulties for the blind to set the way out orientation [2]. They are unable to move according to their expected direction. In indoor navigation they cannot depends on the smart system with GPS to find out the way as the weakness of GPS signal, similarly they also get stuck to set their way out in outdoor environment if it is surrounded by low height obstacles and holes [3]. Researches show that visual impaired person can walk using smart sensory devices [4-9]. However, they failed to provide hole detection features for the blind.

A productive, innovative and efficient smart gadget attached with separated sensors can serve visually impaired help perceptibly hand-off the data back to the user. Innovation must serve and keep on advancing the welfare of these blind people. Individuals are frequently confined to utilizing a smart stick as their premier gadget for indoor and outside route [10-12]. This strategy works when clients touch objects, enabling them to perceive that they are moving toward something [13]. A stick enables the client to 
acknowledge questions through material learning. In any case, dazzle individuals have an exceptionally troublesome time distinguishing things far before them on a walkway or even inside their homes. Inside the family unit condition, the primary constraints to dazzle individuals incorporate fundamental question identification concerning hindrance evasion and route. In other way, researchers were using smart phone to utilize its inertial sensor and GPS to assist blind people to navigate alone by building novel apps [14-17]. Additionally, there are few more works also seen in recent years to help the blind for indoor navigation using apps [18-19]. However, error rate of inertial sensors using for indoor navigation is quite high due to drift of the sensor. Therefore, Wi-Fi can be an option to build a sensor area network to measure the signal direction [20-21]. However, hole detection smart cane is not available to help the visually impaired people.

This work elucidated the origination of a design, improvement of the application, talk of the outcomes, and future research advancement of the smart blind stick. The completely developed utilizes an assortment of detecting systems, including a ultrasonic and laser sensor, LED, vibration motor to build a complete prototype for visual impaired. The ultrasonic and laser sensors recognizes encompassing objects and permits the outwardly disabled to "feel" their environment.

\section{MATERIALS AND METHODS}

At the first part, the smart blind stick is proposed and designed that comply with human ergonomics. The design is focusing on the adult blind, so the design of the stick is adjustable to the different height's blind. Besides that, it is also designed based on experimental results obtained in the preliminary work. At the second part, the working flow of the prototype is elucidated. Furthermore, the schematic diagram also presents to show complete system of prototype. The working flow of the smart blind stick is able to classify the obstacle height and detects the front hole.

\subsection{Design of Smart Blind Stick}

Figure 1 demonstrates the architecture of the proposed smart blid stick for visually impaired people. The main component of the system is microcontroller which is connected with three input devices, i.e., two ultrasonic sensors and a laser sensor. The other actuation components are also connected with the microcontroller, i.e., LED, buzzer and vibration motor.

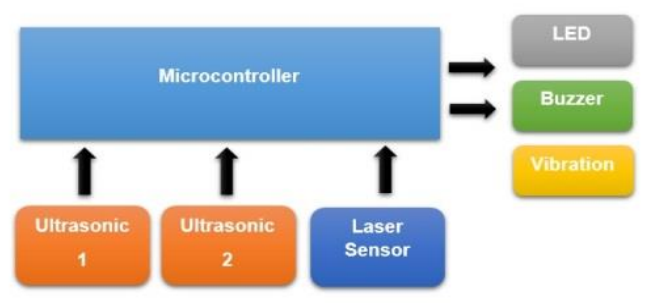

Figure 1. Block diagram of the proposed blind stick

Figure 2 shows the design layout for the walking stick prototype. Firstly, the entire components are placed on a PVC pipe that has $86.5 \mathrm{~cm}$ long. The length of the PVC pipe is chosen because it is suitable length for the blind user to use. Besides that, the microcontroller (Genuino Uno) and motor driver (L293D) is placed in the enclosure box that is placed on the middle of the blind stick. The microcontroller is used to store and running the program code while the motor driver are used to control the vibration motor. Other than that, the buzzer and LED also are placed near the enclosure box. The LED will configured as a status to show which obstacles are detected while the buzzer is configured to alert the blind user when the obstacle are near $20 \mathrm{~cm}$.

Then, the two ultrasonic sensors are placed in lower and upper of the blind stick. The lower part of ultrasonic sensor are placed $17 \mathrm{~cm}$ higher starting below the stick and configure it as low obstacles sensor. The low obstacle sensor will only detect low obstacles. Meanwhile, the upper part of ultrasonic sensor are placed $44.3 \mathrm{~cm}$ higher from the low obstacles sensor and configure it as high obstacles sensor. The high obstacles sensor will only detect high obstacles. For the distance of the ultrasonic sensor placement on the blind stick is identify by referring the experimental results of the ultrasonic sensor coverage and the limit height for low obstacles.

Next, the laser ranging sensor is placed below the low obstacles sensor as shown in Figure 2. This is because to avoid signal interference from other sensors. Besides that, the laser ranging sensor is placed 
$15.2 \mathrm{~cm}$ starting below the stick and configured to detect the front hole. The laser ranging sensor are placed $15.2 \mathrm{~cm}$ higher because the higher the placement of the laser ranging sensor, the further the distance to detect a front hole. Other than that, the laser ranging is tilt down for a 30 degree based on the experimental results for detecting the front hole.

The two vibration motor is placed on the handle of the blind stick and covers it up with a cloth. The vibration motor is configured to alert the blind user when detecting an obstacle. Besides that, microcontroller and motor driver are to function as an alert to the blind user when detecting an obstacle. Finally, the power bank and $9 \mathrm{~V}$ battery is placed on the middle of the blind stick below the enclosure box. The power bank is used to power up the microcontroller while the $9 \mathrm{~V}$ is used to power up the motor driver.

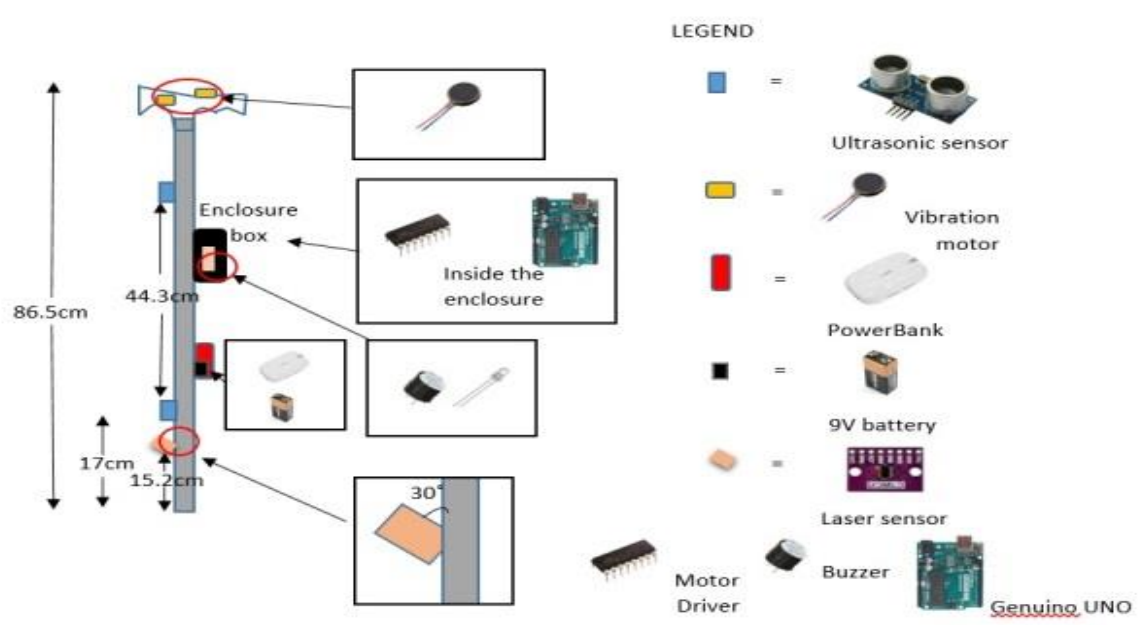

Figure 2. Layout of the smart blind stick

\subsection{Working Flow of the System}

The working flow of the proposed system demonstrates the steps of avoidance higher obstacle and front hole as shown in figure 3. The upper ultrasonic sensor U1 recognize the obstacle from $100 \mathrm{~cm}$ far, then the alarm will off; then the LED1 and vibration motor will turn on. If U1 detect an obstacle, it refers the deterrents are ordered as high obstacle in front. Other than that, if bottom U2 sensor detects an obstacle with a distance of $100 \mathrm{~cm}$, the signal will off; LED2 and vibration will turn on. If U2 identify an obstacle, it implies the low obstacle. However, in these steps if the obstacle within $20 \mathrm{~cm}$ from the user, and then the LED2, ringer and vibration will turn on.

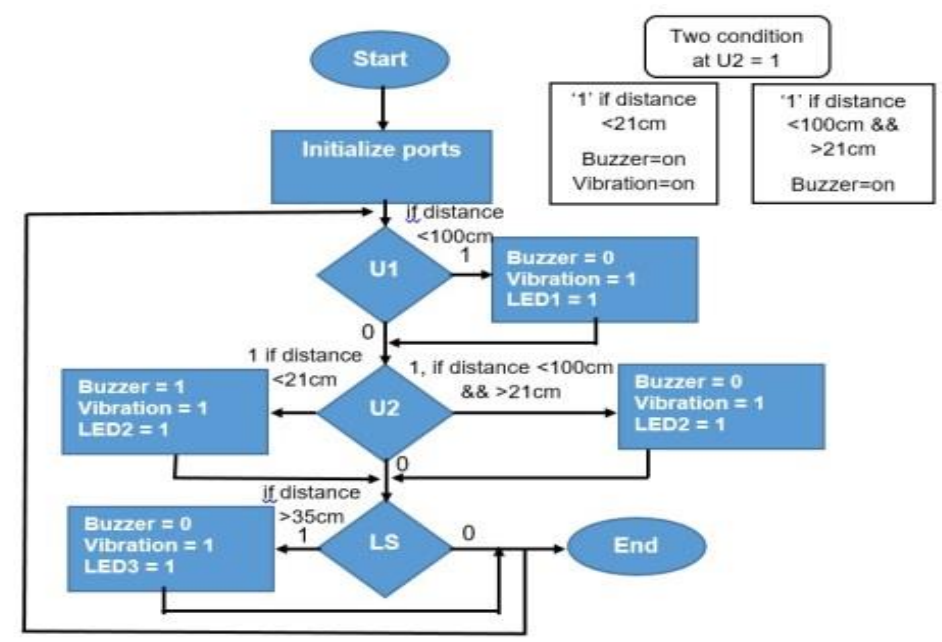

Figure 3. Working flow of the proposed smart walking system for visual impairment 


\section{RESULTS AND DISCUSSION}

\subsection{Simulation of the Smart Walking Stick}

Figure 4 shows schematic diagram of the proposed blind stick system. The schematic diagram contains a microcontroller. In the diagram, the controller is connected with the two HC-SR04 ultrasonic sensors, one VL53L0X laser ranging sensor, the LEDs, the vibration motor and buzzer. In the schematic diagram, there is three HC-SR04 ultrasonic sensor and one VL53L0X laser ranging sensor. Due to unavailability of VL53LOX in the Proteus ISIS software, so, it is replaced by a sensor that has similar function.

Figure 5 shows a simulation test to observe the result of each sensor. Before simulate the schematic design, an additional component and devices need to add to the design that are variable resistor, virtual terminal and oscilloscope. The variable resistor and virtual terminal are important in this simulation because the variable resistor can vary the voltage to change the distance in $\mathrm{cm}$ on the virtual terminal while virtual terminal will shows the distance values based on the variable resistor. The variable resistor will connected to the test pin of each ultrasonic sensor while the virtual terminal will connected to the receiver and transmitter pin of the microcontroller. For the oscilloscope, it shows the different pulses on the ultrasonic sensor based on the distance. The oscilloscope will connected in each of ultrasonic sensor echo pin to observe the pulse.

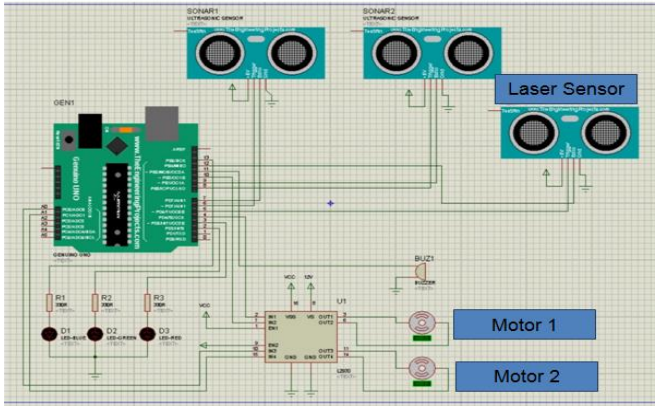

Figure 4. Schematic diagram

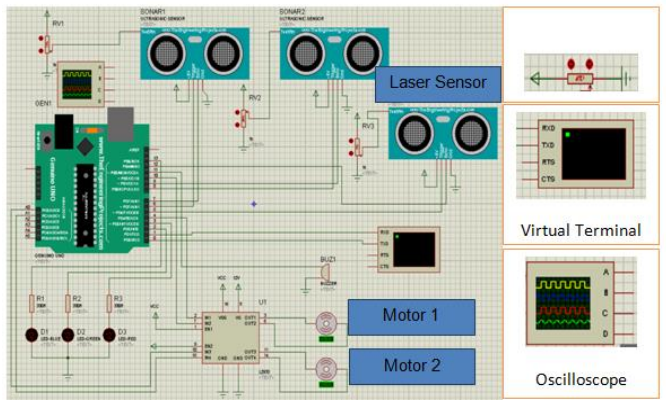

Figure 5. Simulation test

In the simulation process, sonar 1 is declared as high obstacles sensor while sonar 2 is declared as low obstacles sensor. In the virtual terminal, it shows the distance detected by the 1st sensor, 2nd sensor and laser sensor. The 1st and 2nd sensor will be respectively to sonar 1 and sonar 2. Then, the D1, D2 and D3 are declared as status to laser sensor, sonar 1 and sonar 2 respectively. Other than that, the motor 1 and motor 2 is declared as alerting the blind user when detecting obstacles. There is a pattern for the motors for detecting the obstacles such as for high obstacles, only motor 1 will vibrate while for low obstacles; there will be a sequence where motor 1 will vibrate first then the motor 2 will follow. For front hole obstacles, only motor 2 will vibrate. The working flow for this simulation is the same as in the Figure 5.

Figure 6 shows the result of the sonar 1 when the obstacles detected are not within $100 \mathrm{~cm}$. The D2, motor 1 and 2 are off showing that the obstacles are not detected because in the virtual terminal shows the obstacles are $905 \mathrm{~cm}$ away. Figure 7 shows the result of the sonar 1 when the obstacles detected are within $100 \mathrm{~cm}$. The D2, motor 1 are on while motor 2 are off, showing that the obstacles are detected because in the virtual terminal shows the obstacles are $89 \mathrm{~cm}$ away.

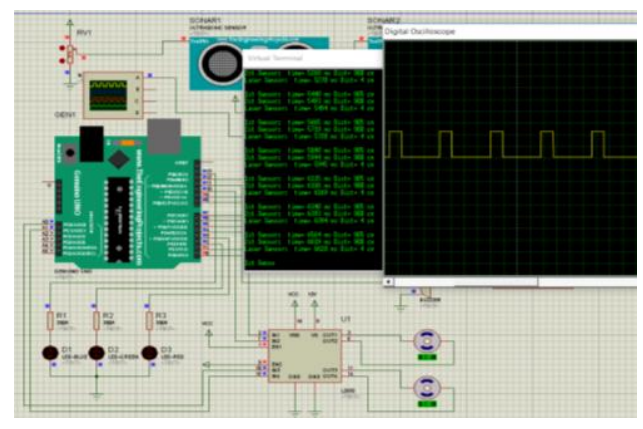

Figure 6. Sonar 1, no obstacle detected

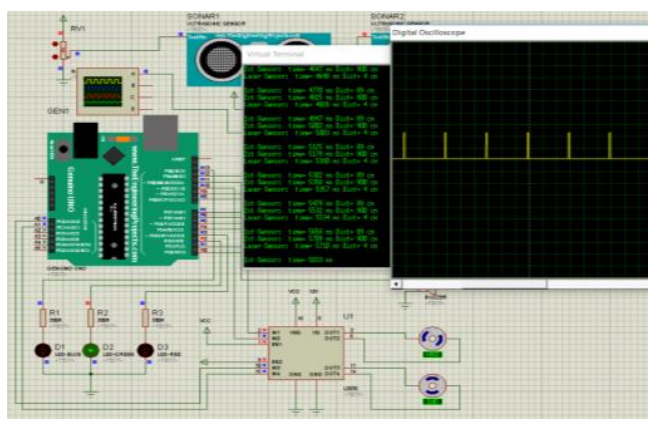

Figure 7. Sonar 1, obstacle detected 
Figure 8 shows the result of the sonar 2 when the obstacles are not detected within $100 \mathrm{~cm}$ distance. The D3, motor 1 and 2 are off, showing that the obstacles are not detected because in the virtual terminal shows the obstacles are $900 \mathrm{~cm}$ away.

Figure 9 shows the result of the sonar 2 when the obstacles detected are within $100 \mathrm{~cm}$. The D3, motor 1 and motor 2 are on showing that the obstacles are detected because in the virtual terminal shows the obstacles are $88 \mathrm{~cm}$ away.

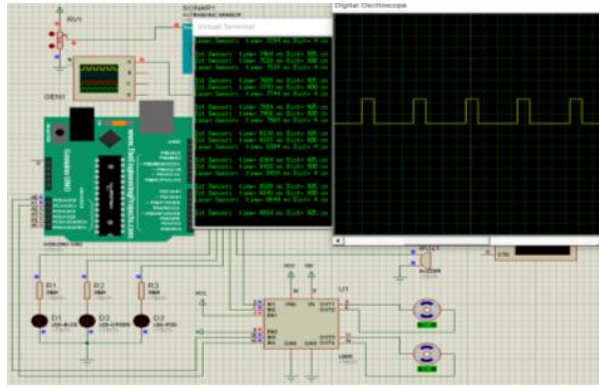

Figure 8. Sonar 2, no obstacle detected

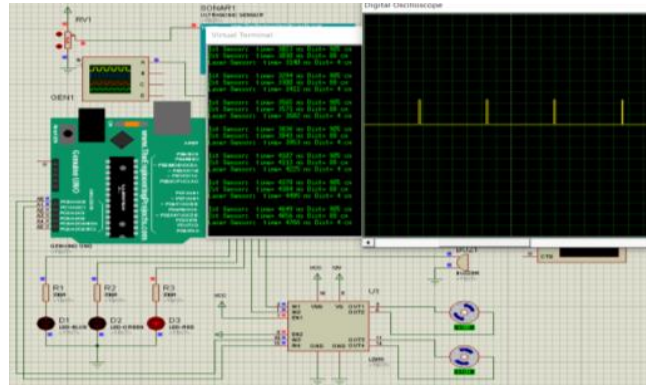

Figure 9. Sonar 2, obstacle detected

Figure 10 shows the result of sonar 2 when the obstacles detected within $20 \mathrm{~cm}$ distance. The D3, motor 1, motor 2 and buzzer are on, showing that the obstacles are nearby because in the virtual terminal shows the obstacles are $10 \mathrm{~cm}$ away.

Figure 11 shows the result of the laser sensor when the front hole detected is not more than $35 \mathrm{~cm}$ far from the subject. The D1, motor 1 and 2 are off, showing that the front hole is not detected because in the virtual terminal shows the front hole detected within $4 \mathrm{~cm}$ distance.

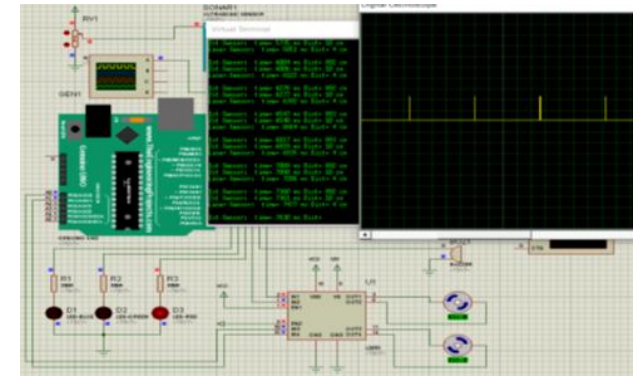

Figure 10. Sonar 2, obstacle near $20 \mathrm{~cm}$

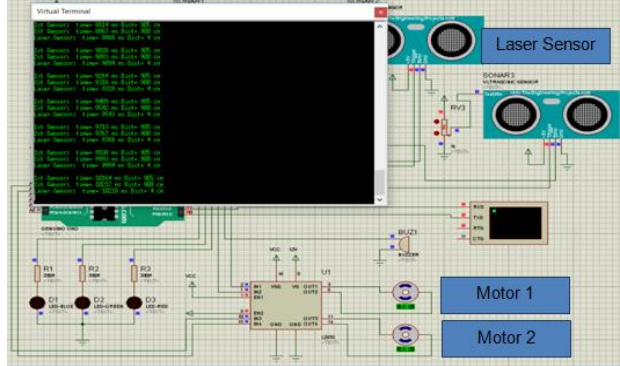

Figure 11. Laser sensor, no front hole

Figure 12 shows the result of the laser sensor when the front hole detected is more than $35 \mathrm{~cm}$ far away. The D1, motor 2 are on while motor 1 is off, showing that the front hole is detected because in the virtual terminal shows the front hole detected within $44 \mathrm{~cm}$.

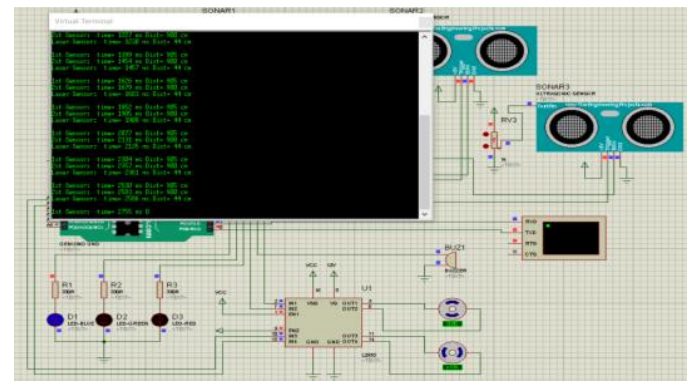

Figure 12. Laser sensor, front hole detected 


\subsection{Experimental setup}

In this work, a set of experiments are conducted to verify the two main functions that is to detect different heights of obstacles and to detect a front hole. The experiment is tested at indoor and outdoor. Figure 13 shows the indoor where the different heights obstacles are tested.
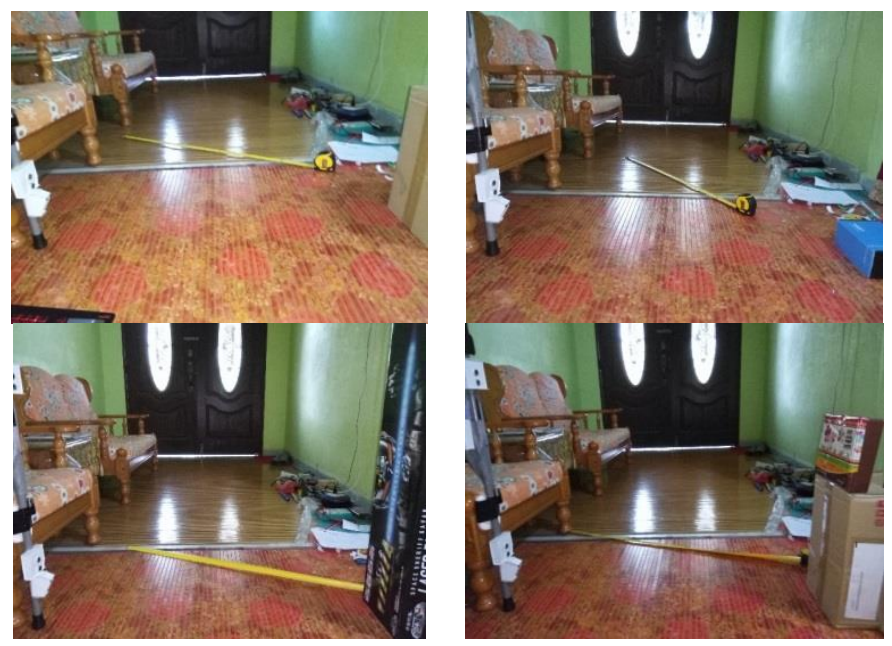

Figure 13. Experiment in indoor environment to differentiate height of obstacles

Figure 14 (a) shows the experiment that took placed at outdoor to verify the function to differentiate the height of obstacles. The different height is detected by the prototype based on sensory input. Figure 14 (b) shows the experiment conducted at outdoor environment for hole detection purpose. In this experiment, the laser sensor attached with the bottom part of the stick is able to detect the hole and send the information to the vibration motor to alarm the blind user.

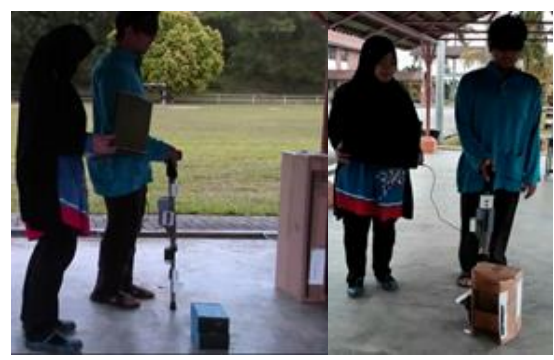

(a)

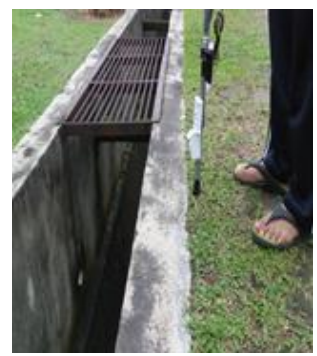

(b)

Figure 14. Outdoor testing to verify the two function: (a) avoid different height obstacles, (b) avoid front hole

\subsection{Experimental Results for Front Obstacle}

Figures 15, 16 and 17 show the result of different height obstacles. The result shows only the Ultrasonic Low sensor detects the obstacle with an average of $100.285 \mathrm{~cm}$ while the Ultrasonic High sensor detects an average of $596.632 \mathrm{~cm}$. It shows the percentage of error for ultrasonic low sensor about $-0.29 \%$ while the Ultrasonic High has higher error about 496.32\%. In this experiment, the obstacle is categorized as the low obstacle. 


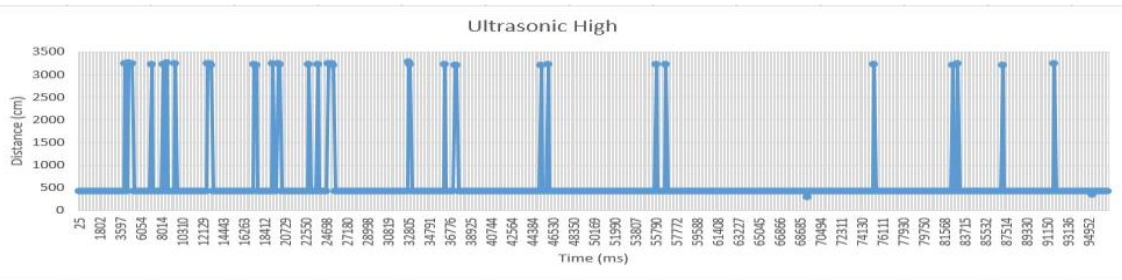

Ultrasonic Low

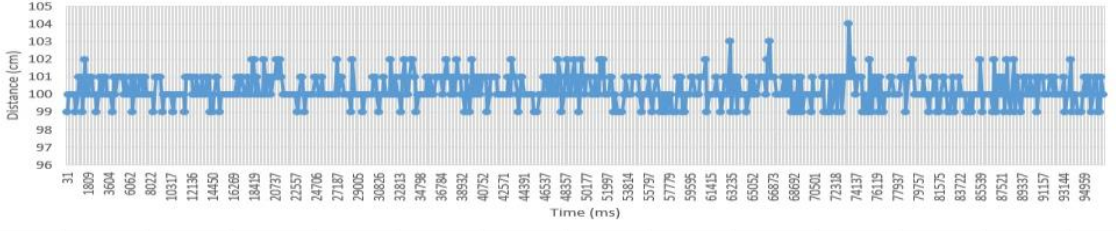

Figure 15. Graph of Ultrasonic Sensor for lower height obstacle

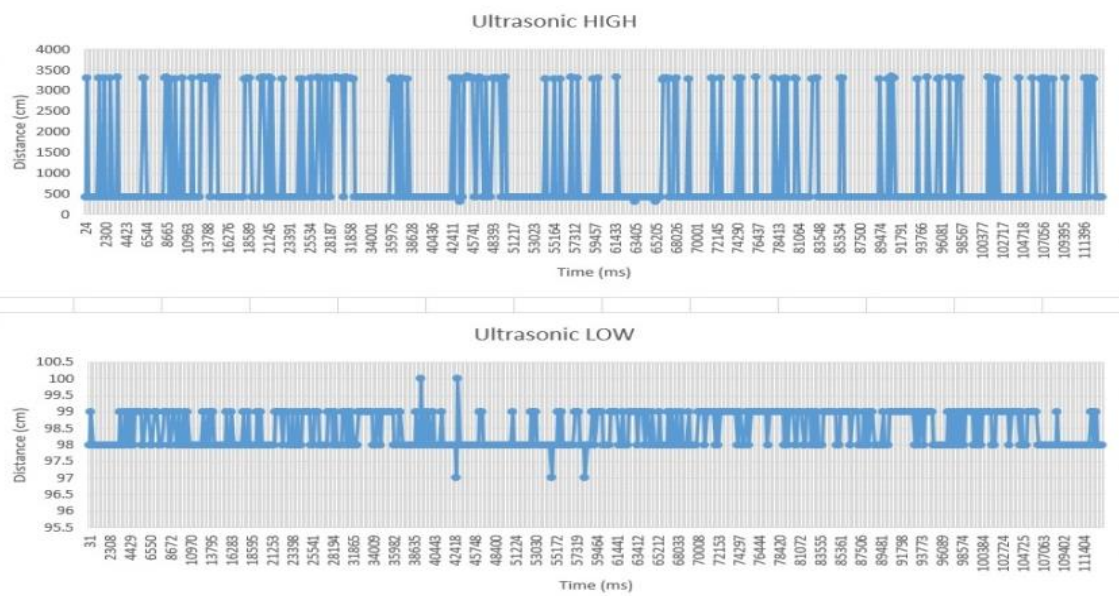

Figure 16. Graph of Ultrasonic Sensor for low height obstacle

The obstacle height for this experiment is about $37.2 \mathrm{~cm}$. In Table 1 , the result shows only the Ultrasonic Low sensor detects the obstacle with an average of $98.445 \mathrm{~cm}$ while the Ultrasonic High sensor detects an average of $1096.39 \mathrm{~cm}$. Besides that, it shows the error is less error for Ultrasonic Low sensor that is about $-1.56 \%$ while the Ultrasonic High has higher error about $996.39 \%$. So for this experiment, the obstacle is categorized as the low obstacle.

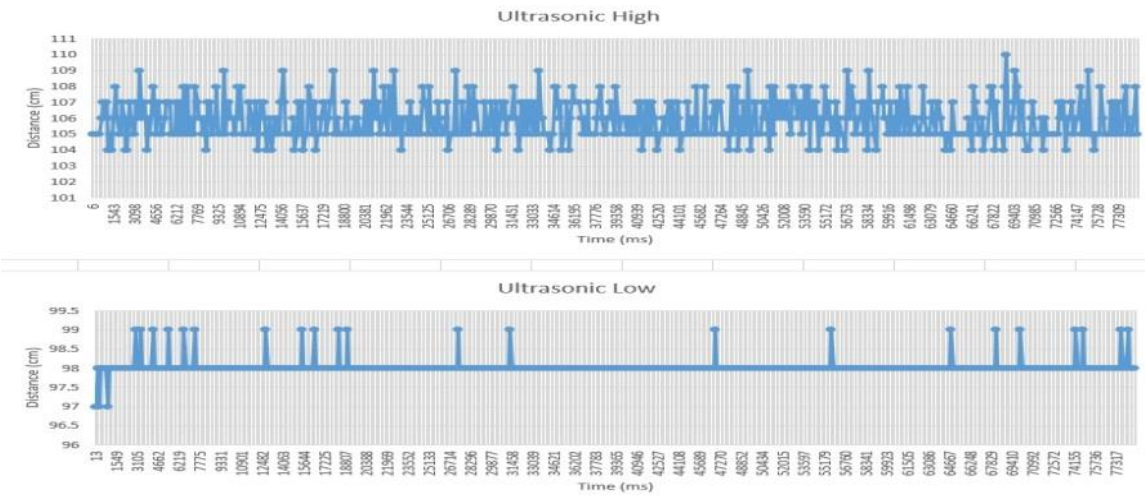

Figure 17. Graph of Ultrasonic Sensor for medium height obstacle at $100 \mathrm{~cm}$ 
The obstacle height for this experiment is about $55 \mathrm{~cm}$. In Table 1 , the result shows only the Ultrasonic Low sensor detects the obstacle with an average of $98.032 \mathrm{~cm}$ while the Ultrasonic High sensor detects an average of $105.88 \mathrm{~cm}$. Besides that, the error also shows there is less error for the Ultrasonic Low sensor that is about $-1.97 \%$ while the Ultrasonic High has higher error about $5.88 \%$. So for this experiment, the obstacle should be categorized as the low obstacle but it is already has been determined that if the height of the obstacles is more than $40 \mathrm{~cm}$, it is considered as high obstacle.

For this experiment, the Ultrasonic High sensor detection is only 5.88\% error. This is because it has limitation for ultrasonic sensor. Ultrasonic sensor emits sonar wave in different angle up about to 30 degrees. So different angles have different distances considered that the obstacles are $100 \mathrm{~cm}$ away from the user.

\subsection{Experimental Results for Hole Detection}

Figure 18 shows the result of hole detection. When there is no front hole for night, the average distance detected by laser ranging sensor is $264.2 \mathrm{~mm}$. The result for front hole detection will be recorded when there is increase than the result for no front hole detection.

The result when there is a front hole for night, the average distance detected is $8072.08 \mathrm{~mm}$. Besides that, the detected front hole is about $21.5 \mathrm{~cm}$ far from user. It is less than the distance detected in Location A when detected the front hole.

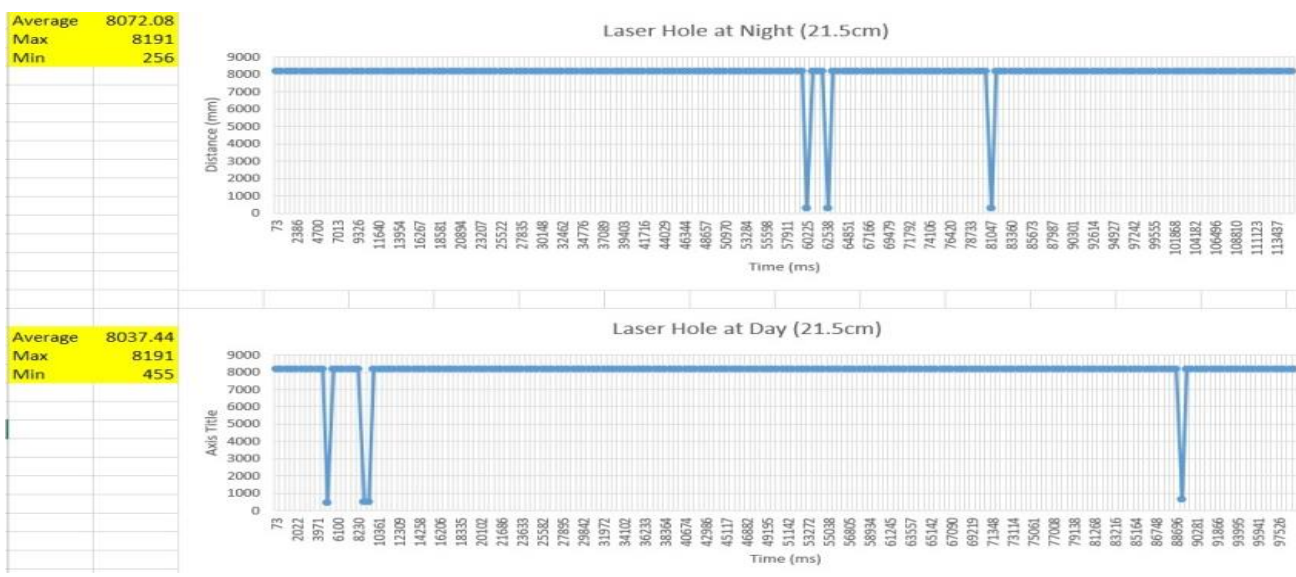

Figure 18. Graph of Laser Ranging Sensor

\section{CONCLUSIONS}

The smart blind stick prototype has successfully designed and analyzed this paper. The newly designed stick complies with the human ergonomics because it is developed for adult users. The blind stick prototype is tested for different heights of obstacles and for the the front hole. In this work, two ultrasonic sensors are used to detect a different height of obstacles whether it is high or low and one laser ranging sensor is used to detect a front hole. The smart blind stick is able to detect the obstacles with the height bellow $40 \mathrm{~cm}$, is considered low obstacle, on the other hand, if the detection height is more than $40 \mathrm{~cm}$, it is considered high obstacles. Additionally, the laser ranging sensor has successfully tested for hole detection. The blind stick is able to detect the front hole while the stick is around $21.5 \mathrm{~cm}$ far from the hole. Therefore this novel blind stick is capable to assist a blind person to move independently.

\section{REFERENCES}

[1] Groen II, Silson EH, Baker CI. Contributions of low-and high-level properties to neural processing of visual scenes in the human brain. Phil. Trans. R. Soc. B. 2017 Feb 19;372(1714):20160102.

[2] Kan, Kilic D, Dogan F. Way finding strategies of blind persons in urban scale. PsyCh journal. 2017 Dec 1;6(4):30315 .

[3] Van Erp JB, Kroon L, Mioch T, Paul KI. Obstacle Detection Display for Visually Impaired: Coding of Direction, Distance, and Height on a Vibrotactile Waist Band. Frontiers in ICT. 2017 Oct 13;4:23.

[4] Bischof A, Lefeuvre K, Kurze A, Storz M, Totzauer S, Berger A. Exploring the Playfulness of Tools for CoDesigning Smart Connected Devices: A Case Study with Blind and Visually Impaired Students. InProceedings of the 2016 Annual Symposium on Computer-Human Interaction in Play Companion Extended Abstracts 2016 Oct 16 (pp. 93-99). ACM. 
[5] Chebat DR, Harrar V, Kupers R, Maidenbaum S, Amedi A, Ptito M. Sensory substitution and the neural correlates of navigation in blindness. In Mobility of Visually Impaired People 2018 (pp. 167-200). Springer, Cham.

[6] Linn T, Jwaid A, Clark S. Smart glove for visually impaired. InComputing Conference, 2017 Jul 18 (pp. 13231329). IEEE.

[7] Gori M, Cappagli G, Tonelli A, Baud-Bovy G, Finocchietti S. Devices for visually impaired people: High technological devices with low user acceptance and no adaptability for children. Neuroscience \& Biobehavioral Reviews. 2016 Oct 1;69:79-88.

[8] Ramirez AR, Gonzalez-Carrasco I, Jasper GH, Lopez AL, da Silva RF, Crespo AG. Towards Visually Impaired Autonomy in Smart Cities: The Electronic Long Cane Project. In Design Solutions for User-Centric Information Systems 2017 (pp. 341-365). IGI Global.

[9] Andò B, Baglio S, Marletta V, Valastro A. A haptic solution to assist visually impaired in mobility tasks. IEEE Transactions on Human-Machine Systems. 2015 Oct;45(5):641-6.

[10] Motta G, Ma T, Liu K, Pissaloux E, Yusro M, Ramli K, Connier J, Vaslin P, Li JJ, De Vaulx C, Shi H. Overview of Smart White Canes: Connected Smart Cane from Front End to Back End. In Mobility of Visually Impaired People 2018 (pp. 469-535). Springer, Cham.

[11] Ang LM, Seng KP, Heng TZ. Information communication assistive technologies for visually impaired people. Smart Technologies: Breakthroughs in Research and Practice: Breakthroughs in Research and Practice. 2017 Jun 19:17.

[12] Guevarra EC, Camama MI, Cruzado GV. Development of Guiding Cane with Voice Notification for Visually Impaired individuals. International Journal of Electrical and Computer Engineering (IJECE). 2018 Feb 1;8(1):10412.

[13] Mikulowski D. An Approach for Ontologically Supporting of Space Orientation Teaching of Blind Pupils Using Virtual Sound Reality. In International Conference on Interactive Collaborative Learning 2017 Sep 27 (pp. 753-759). Springer, Cham.

[14] Abdolrahmani A, Easley W, Williams MA, Ronquillo E, Branham S, Chen T, Hurst A. Not all errors are created equal: Factors that impact acceptance of an indoor navigation aid for the blind. In Proceedings of the 18th International ACM SIGACCESS Conference on Computers and Accessibility 2016 Oct 23 (pp. 301-302). ACM.

[15] Rodriguez-Sanchez MC, Martinez-Romo J. GAWA-Manager for accessibility Way finding apps. International Journal of Information Management. 2017 Dec 1;37(6):505-19.

[16] Meliones A, Sampson D. Blind MuseumTourer: A System for Self-Guided Tours in Museums and Blind Indoor Navigation. Technologies. 2018 Jan 4;6(1):4.

[17] Mataró TV, Masulli F, Rovetta S, Cabri A, Traverso C, Capris E, Torretta S. An assistive mobile system supporting blind and visual impaired people when are outdoor. In Research and Technologies for Society and Industry (RTSI), 2017 IEEE 3rd International Forum on 2017 Sep 11 (pp. 1-6). IEEE.

[18] Liu KC, Wu CH, Tseng SY, Tsai YT. Voice Helper: A Mobile Assistive System for Visually Impaired Persons. In Computer and Information Technology; Ubiquitous Computing and Communications; Dependable, Autonomic and Secure Computing; Pervasive Intelligence and Computing (CIT/IUCC/DASC/PICOM), 2015 IEEE International Conference on 2015 Oct 26 (pp. 1400-1405). IEEE.

[19] Mullen SP, Palac DE, Bryant LL. Maps to apps: Evaluating wayfinding technology. In Community Wayfinding: Pathways to Understanding 2016 (pp. 137-151). Springer, Cham.

[20] Suherman S. WiFi-Friendly Building to Enable WiFi Signal Indoor. Bulletin of Electrical Engineering and Informatics. 2018 Jun 1;7(2).

[21] Priya A, Sasilatha T. Wireless Network For Strategic Boundary Supervision System. Bulletin of Electrical Engineering and Informatics. 2017 Dec 1;6(4):367-70. 